\title{
THE EFFECTS OF ASH DEPOSITION ON A TRANSONIC TURBINE GUIDE VANE
}

\author{
Yun Zheng \\ Beihang University \\ Zheng_yun@buaa.edu.cn \\ Beijing, China
}

\author{
Dong Sun \\ Beihang University \\ sundong_1001@163.com \\ Beijing, China
}

\author{
Hui Yang \\ Beihang University \\ huiyang@buaa.edu.cn \\ Beijing, China
}

\section{ABSTRACT}

Effects of ash deposition on a transonic turbine guide vane are studied numerically. By incorporating the critical velocity sticking model in the commercial fluid dynamics software-FLUENT, the two-dimensionnal, steady ReynoldsAveraged Navier-Stokes(RANS) equations are solved for the clean vane and then the ash deposition rate on the turbine guide vane surface is acquired. Then the turbine vane pressure surface is set roughness based on the ash deposition rate. Two roughness setting strategies are adopted. One of them is setting average roughness and the other is setting variable roughness according to the fitting curve of the ash deposition rate. Lastly, the flow field of the guide vane with different roughness is calculated to investigate the effects of ash depositon on the aerodynamic performance of the turbine vane. The differences of results caused by the above two roughness setting strategies are also discussed.

The distribution of deposition rate on the vane surface indicates that ash particles are mostly deposited on the blade pressure surface and that deposition rate has a drastic fluctuation, which may cause rapidly increasing roughness on the blade surface. By comparing the blade flow field with different blade surface roughness, it is found that surface roughness has little effects on the mach ditribution along the blade surface but increases the blade surface friction and the total pressure loss observably. Furthermore, results show that the variable roughness on the blade pressure surface has smaller effects on the blade aerodynamic performance than those caused by uniform roughness.

\section{INTRODUCTION}

When the plane flies in harsh environment, such as sandstorm, smog and volcanic dust clouds, the solid particles in these environment can enter the power stream of gas turbines(e.g. Grant and Tabakoff, 1975; Walsh and Thole and Joe, 2006 ). when the ingested particles pass through the combustion chamber, some physical and chemical changes can occur in them. there is no method to filter out these particles completely. Besides, EI-Batsh and
Haselbacher(2002) found that the combustion of low-grade fuels, such as crude oils and biomass which always contain a lot of impurities, can produce large amounts of particles. These particles may flow to the turbine components along with the gas. In the future, under the pressure of political and envirenment concerns, the liquefaction and gasification of coal could become an alternative fuel for turbine engines to replace traditional petroleum based fuels, but the challenge is that the coal derived fuels can produce more pullutants during combustion(e.g. Barker and Casaday, 2012). The ingested solid particles can deposit on the internal surface of the engine and increase the surface roughness or change the shape of blades. The consequence is degrading the performance and stability of gas turbines. In the most severe cases, the injested particles are sufficient to cause outright failure of the engine and the engines can shut down due to the deposits(e.g. Tabakoff, 1987). So understanding how the particles deposite on the internal wall and how the deposits affect the aerodynamic performance of turbo-engine is significant.

Kawagishi and Nagao(1992) conducted a experiment using a single stage turbine to study the effects of deposits on turbine performance. He found that the stage efficieny was decreased by about $20 \%$ due to particle deposition. Bolcs and Sari(1988) found that the deposits on the turbine could increase the surface roughness and the large roughness could make the boundary layer of turbine blade suface become turbulent and thicker. Dunn and Baran(1996) found that the deposits on the high-pressure turbine could clog cooling holes. In this situation, the life of engine can be reduced due to thermal stresses and overheating. Bons(2010) confirmed that surface roughness can decrease turbine performance. Abuaf and Bunker(1998) found losses and heat transfer are related to surface roughness.

With the development of computational fluid dynamics(CFD), numerical research of deposition have become a focus. EI-Batsh and Haselbacher(2002) provided a criteria for particle deposition. Tafti and Sreedharan(2010) used the coal ash composition to estimate the sticking probability according to the viscosity-temperature 
relationship. however, there is little numerica research into the relationship between the deposition and surface roughness. Most numecical model of depositon did not account for the effects of surface roughness. Besides, the majority of roughness works related to gas turbines is based on equivalent sandgrain roughness suggested by Schlichting(1979). But the truth is that pratical roughness character due to deposition is not spatially uniform. So applying a uniform roughness level to the turbine surface may produce misleading results.

In this work, the relationship between particle deposition and surface roughness and the effects of uniform and variable roughness on the turbine aerodynamic performance are investigated numerically. In the first step, the flow field of a clean transonic turbine guide vane was solved using the commercial computational fluid dynamics software-FLUENT and the trajectories of the ash particles were tracked by the use of DPM. In the meanwhile, the critical velocity sticking model was added to the FLUENT software to study the depositon characteristics and to acquire the data of deposition rate on the turbine vane. In the second step, two roughness setting strategies on the blade pressure surface are adopted. One of them is setting uniform roughness based on the deposition rate and the other is setting variable roughness according to the fitting curve acquired from the same deposition data. In the last step, the flow field of turbine vane with different roughness was solved and the data were compared with the results of the clean blade calculated in the first step. The differences of results caused by the above two roughness setting strategies were also discussed. To the authors' knowledge, there are no similar studies to investigate the effects of deposition on turbine blade performance by the means of variable roughness. So the method in this work to account for the relationship between ash deposition and roughness makes new try a bit.

\section{METHODOLOGY}

Following the outline in Figure 1, the ash particles deposition rate and performance of the turbine vane are calculated. Firstly, the FLUENT steady solver calculates the two-dimensional flow field of the smooth blade. Then, the particles are seeding in the flow field and tracked until they reach the boundaries of the computational domain. If the particles hit the surface of the blade, the process of deposition calculation is activated using the critical velocity model. If the particles reflect from the blade surface, the reflecting velocity is calculated and then the reflected particles are continued to be tracked. When the deposition calculation is finished, the surface roughness of the blade is modified. Finally, the flow field of the rough blade is evaluated and compared to that of the smooth blade. In the following of this section, the critical velocity model, particles reflecting mechanism, and roughness model are introduced, respectively.

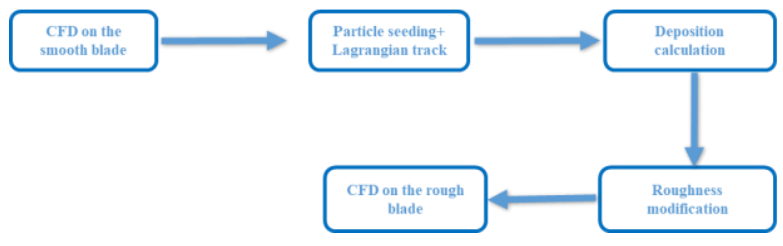

Figure 1 Outline of the procedure

\section{Critical velocity sticking model}

The critical impact velocity is introduced to determine if the particles stick to the blade surface. The formula is given as:

$$
\begin{gathered}
V_{c r}=\left(\frac{2 E}{D_{p}}\right)^{\frac{10}{7}} \\
\mathrm{E}=0.51\left[\frac{5 \pi^{2}\left(k_{1}+k_{2}\right)}{4 \rho_{p}^{\frac{3}{2}}}\right]^{\frac{2}{5}} 1 \\
k_{1}=\frac{1-v_{s}^{2}}{\pi E_{s}}(3) \\
k_{2}=\frac{1-v_{p}^{2}}{\pi E_{p}}(4) \\
E_{p}=3 \times 10^{20} \exp \left(-0.02365 T_{g}\right)
\end{gathered}
$$

Where $V_{c r}$ is the critical velocity. The quantity is affected by various properties of the flow and particle. $\mathrm{E}$ is the composite Young's modulus, $E_{s}$ is the surface Young's modulus with the value equals $2.15 \times 10^{14}$ in this study, $E_{p}$ is the particle Young's modulus calculated by use of fomula (5). $T_{g}$ is the free stream gas temperature above the surface. $v_{s}$ is the blade surface Poisson ratio and $v_{p}$ is the particle Poisson ratio. In this work, both $v_{s}$ and $v_{p}$ equal 0.27 . If the normal velocity of the particle impacting the blade surface is below the critical velocity, the particle will deposite on the surface. Otherwise, the particle will reflect off the blade surface.

The particle detachment mechanism is applied to detemine if the particle deposited on the blade surface will be removed by the fluid force. To do this, EI-Batsh(2002) introduced a new quantity, the critical wall shear velocity given as:

$$
u_{\tau c}^{2}=\frac{C_{u} W_{A}}{\rho d_{p}}\left(\frac{W_{A}}{d_{p} K_{c}}\right)^{1 / 3}(6)
$$

Where $W_{A}$ is the work of sticking with the units of $\mathrm{J} / \mathrm{m}^{2}$. It depends on the material properties of the particle and the surface. $C_{u}$ is the Cunningham correction factor. When the local wall friction velocity is above the critical wall shear velocity, the paticle will be removed from the blade surface. 


\section{Reflecting mechnism}

If the particle attacks the blade surface, it will reflect off the surface if not deposit. But the reflected particle will lose a part of its kinetic energy. The process is dependent upon the incident velocity and the material properties of the particle and solid wall. Figure 2 shows the process of the particle reflection. The particle rebounding conditions are determined using the tangetial restitution parameter $e_{t}$ and the normal restitution parameter $e_{n}$ which are given as:

$$
\begin{gathered}
e_{t}=\frac{V_{t 2}}{V_{t 1}}=A_{0}+A_{1} \beta_{1}+A_{2} \beta_{1}^{2}+A_{3} \beta_{1}^{3}+A_{4} \beta_{1}^{4} \\
e_{n}=\frac{V_{p n 2}}{V_{p n 1}}=B_{0}+B_{1} \beta_{1}+B_{2} \beta_{1}^{2}+B_{3} \beta_{1}^{3}+B_{4} \beta_{1}^{4} \\
\operatorname{tg} \beta_{1}=\frac{V_{n 1}}{V_{t 1}}(9)
\end{gathered}
$$

where $\beta_{1}$ represents the particle impingement angle. $A_{0} \sim A_{4} 、 B_{0} \sim B_{4}$ are all experimental constants related to the material propertites of the particle and solid surface. In this work, those constants are adopted according to Table 1 recommended by Tabakoff and Metwally(1992).

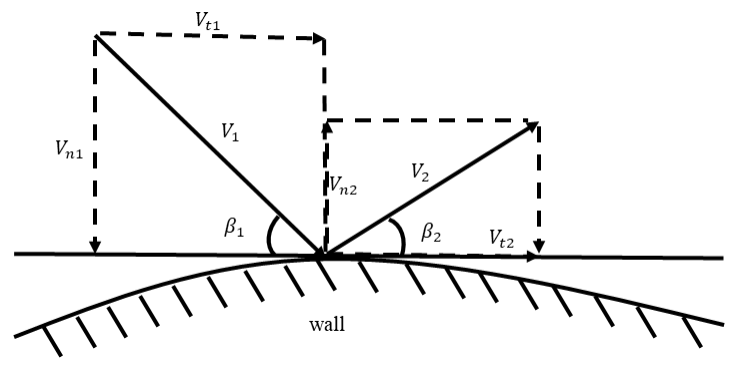

Figure 2 particle reflects off the wall surface

\begin{tabular}{|c|c|c|c|c|}
\hline $\boldsymbol{A}_{\mathbf{0}}$ & $\boldsymbol{A}_{\mathbf{1}}$ & $\boldsymbol{A}_{\mathbf{2}}$ & $\boldsymbol{A}_{\mathbf{3}}$ & $\boldsymbol{A}_{\mathbf{4}}$ \\
\hline 1.0 & $-8.322 \boldsymbol{e}^{-\mathbf{3}}$ & $-8.095 \boldsymbol{e}^{-\mathbf{5}}$ & $1.786 \boldsymbol{e}^{-\mathbf{6}}$ & 0.0 \\
\hline $\boldsymbol{B}_{\mathbf{0}}$ & $\boldsymbol{B}_{\mathbf{1}}$ & $\boldsymbol{B}_{\mathbf{2}}$ & $\boldsymbol{B}_{\mathbf{3}}$ & $\boldsymbol{B}_{\mathbf{4}}$ \\
\hline 1.0 & $8.098 \boldsymbol{e}^{-\mathbf{3}}$ & $-1.226 \boldsymbol{e}^{-\mathbf{3}}$ & $2.309 \boldsymbol{e}^{-\mathbf{5}}$ & $-1.292 \boldsymbol{e}^{-\mathbf{7}}$ \\
\hline
\end{tabular}

Table 1 Particle rebounding constants

\section{Roughness model}

To investigate the wall roughness effects in turbulent wall-bounded flows, the FLUENT software modifies the law of the wall for mean velocity to the form:

$$
\frac{u_{p} u^{*}}{\tau_{w} / \rho}=\frac{1}{\kappa} \ln \left(E \frac{\rho u^{*} y_{p}}{\mu}\right)-\Delta B(10)
$$

Where

$$
\begin{gathered}
u^{*}=C_{\mu}^{1 / 4} k^{1 / 2} \\
\Delta B=\frac{1}{k} \ln f_{r}
\end{gathered}
$$

Where $f_{r}$ is a roughness function that quantifies the shift of the intercept due to roughness effects.

$\Delta B$ is related to the nondimensional roughness height, $K_{s}^{+}$.

$$
K_{s}^{+}=\frac{\rho K_{s} u^{*}}{\mu}(13)
$$

When $K_{s}^{+} \leq 2.25$ which is called to be the hydrodynamically smooth regime:

$$
\Delta B=0(14)
$$

When $2.25<K_{S}^{+} \leq 90$ which is the transitional regime:

$$
\begin{aligned}
\Delta B=\frac{1}{k} \ln \left[\frac{K_{s}^{+}-2.25}{87.75}+C_{s} K_{s}^{+}\right] \\
\quad \times \sin \left\{0.4258\left(\ln K_{s}^{+}-0.811\right)\right\}
\end{aligned}
$$

When $K_{S}^{+}>90$ which is the fully rough regime:

$$
\Delta B=\frac{1}{k} \ln \left(1+C_{s} K_{s}^{+}\right)(16)
$$

Where $C_{S}$ is a roughness constant related to the type of the roughness.

\section{RESULTS AND DISCUSTION}

\section{FLOW FIELD OF THE SMOOTH BLADE}

The Von Karman Institute(VKI) transonic inlet turbine guide vane was selected as the computational physical model. The blade profile is chosen from the literature for which flow field measurements are available in Arts and Lambert(1990). The flow field of the smooth blade was solved using two-dimensional unstructured grid. To confirm grid independent solution, the grid sensitivity study is conducted by employing two grids with 80000 and 100000 cells. Figure 3 shows the whole grid of the computational domian and a part of grid near the blade leading edge and trailing edge. The computational domain extends 1.35 axial chord lengths upstream and 1.16 axial chord lengths downstream. The grid near the blade surface has been refined to ensure that the $y^{+}$value of the converged solution is near to 1 at all blade surface locations. Table 2 gives the boundary conditions used for the smooth blade. The $\kappa-\omega$ SST turbulence model is deployed to solve the two-dimensional, compressible flow field. Figure 4 shows the distribution of static pressure of blade surface with two grids and experimental data. The figure indicates that the results of numerical calculations using two grids are completely same. So it can be confirmed that the solution of flow field is grid independent. Furthermore, it can also be seen from the figure that the numerical data agree well with experiment data in the most parts of the blade surface. But beginning wth the location of about 60 percent of axial chord on the blade suction surface, there is big discrepancy between numerical and experimental data. To solve the problem, a better turbulent model is needed. Figure 5 shows the contours of local velocity. In the next section, the solution of flow field was used for particles deposition simulation. 


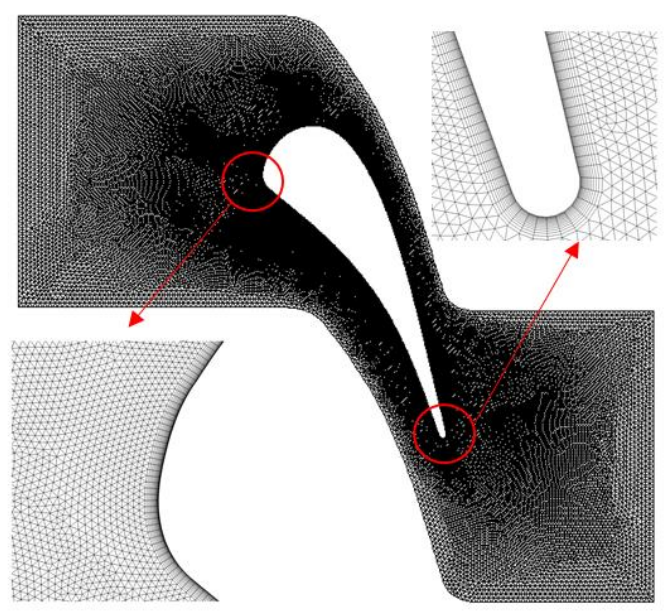

Figure 3 The VKI turbine guide vane grid used in FLUENT flow solver

\begin{tabular}{|c|c|}
\hline Isentropic exit Mach number & 0.875 \\
\hline Total inlet pressure, $[\mathrm{Pa}]$ & 147500 \\
\hline Total inlet temperature, $[\mathrm{K}]$ & 1500 \\
\hline Free stream turbulence, $[\%]$ & 1 \\
\hline Static outlet pressure, $[\mathrm{Pa}]$ & 89600 \\
\hline Wall temperature, $[\mathrm{K}]$ & insulated \\
\hline
\end{tabular}

Table 2 Flow field boundary conditions

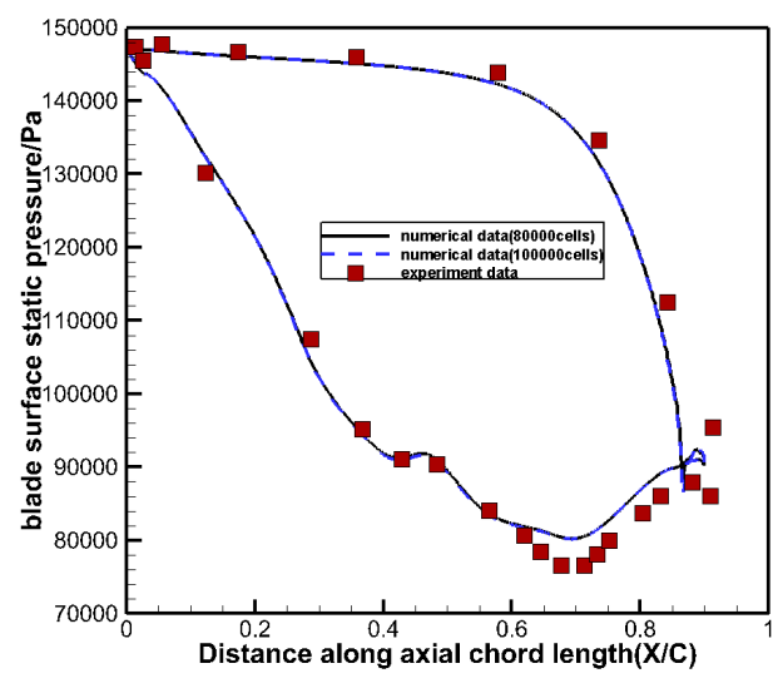

Figure 4 Comparison of static pressure distribution on the blade surface

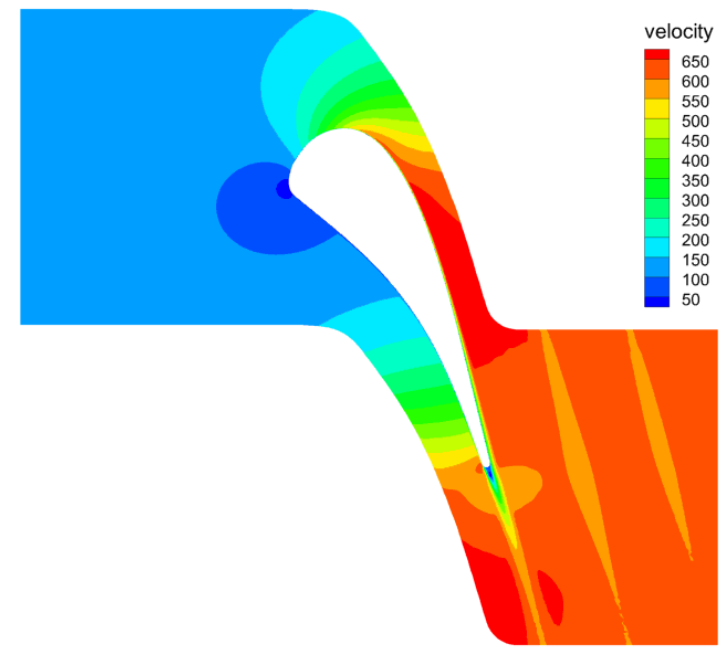

Figure 5 Contours of local velocity

\section{Deposition characteristics}

The particles are injected at the inlet of the computational domain with the velocity and temperature equal to the local fluid velocity and local fluid temperature, respectively. Table 3 shows the particle properties. In order to simulate the diameter distribution of actual particles, the particles are assumed to meet the Rosin-Rammler distribution. Table 4 shows the particles diameter distribution. According to data in Table 4 and RosinRammler equation(17), we abtain the characteristic diameter $\bar{d}$ which is 13.4 um and the spread number $\mathrm{n}$ which is 1.016 . EI-Batsh and Hesham(2001) found that the particles produced by the combustion of the low-quality fuels are in the size range from $0.25 \mu \mathrm{m}$ to $20 \mu \mathrm{m}$. the particles size range was also adopted in this work.

After injected from the inlet of flow field, the trajectories of all particles are calculated until they leave the flow field or deposit on the blade surface. Once attacking the surface of the blade, the critical velocity sticking model is activated to judge if the particle would attach to the wall. If not, the particle reflecting model is activated to calculate the particles' reflecting velocity and then the trajectories of the reflected particles are continued to be calculated.

$$
Y_{d}=e^{-(d / \bar{d})^{n}}
$$

\begin{tabular}{|c|c|c|c|}
\hline $\mathrm{d}(\mathrm{um})$ & $\rho\left(\mathrm{kg} / \mathrm{m}^{3}\right)$ & $c_{p}(J / \mathrm{kg} \cdot \mathrm{K})$ & $\mathrm{K}(\mathrm{W} / \mathrm{m} \cdot \mathrm{K})$ \\
\hline 13.4 & 990 & 984 & 0.5 \\
\hline
\end{tabular}

Table 3 Ash particle properties

\begin{tabular}{|c|c|}
\hline Diameter & Mass fraction \\
\hline Size $[\mu \mathrm{m}]$ & Ratio[\%] \\
\hline $0-5$ & 26.3 \\
\hline $5-10$ & 22.2 \\
\hline
\end{tabular}




\begin{tabular}{|c|c|}
\hline $10-20$ & 21.3 \\
\hline $20-40$ & 20.8 \\
\hline $40-60$ & 9.4 \\
\hline
\end{tabular}

\section{Table 4 Diameter distribution of the ash particle}

Figure 6 shows the distribution of particles deposition rate along the blade pressure surface shown by the black line and suction surface shown by the red line. It is found that the deposition rate on the blade pressure surface is much faster than that on the blade suction surface and that the depositon rate in most parts of suction surface equals to zero. It means that the particles are mostly deposited on the blade pressure surface. The result is consistent with the result of Barker and Casaday(2012). They found that particulate deposited only on the initial $18 \%$ of the wetted distance of the suction surface of the vane. On the pressure surface, the deposition rate is faster in the middle area than that near the leading edge and tailing edge. It is because the wall shear stress near the leading edge and tailing edge is much bigger so that the particles are not deposited easily in these areas. It can also be seen that the deposition rate near the leading edge and tailing edge fluctuates sharply. The reason is that the flow field parameters such as temperature and pressure change quikly in these areas and that these parameters affect the particle depositon dramatically. Figure 7 shows the static temperature distribution on the blade surface. The temperature near the leading edge and tailing edge change more quickly than that on the other parts of the suction surface. The pressure distribution on the blade surface can refer to Figure 4. In this situation, the blade surface near the leading edge and tailing edge will get much bigger roughness than that in other parts of the blade surface. On the suction surface, the particles are mostly deposited in the area near the leading edge and the deposition rate in this area fluctuates sharply as well. Except for the area near the blade leading edge, the particles are seldom deposited. Note that some particles reflecting off the opposite pressure surface will deposite on the blade suction surface.

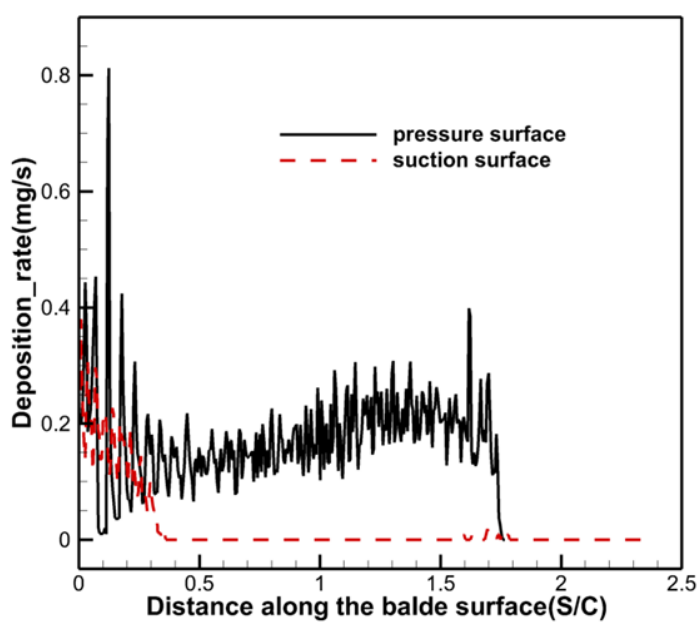

Figure 6 Depositon rate along the blade surface

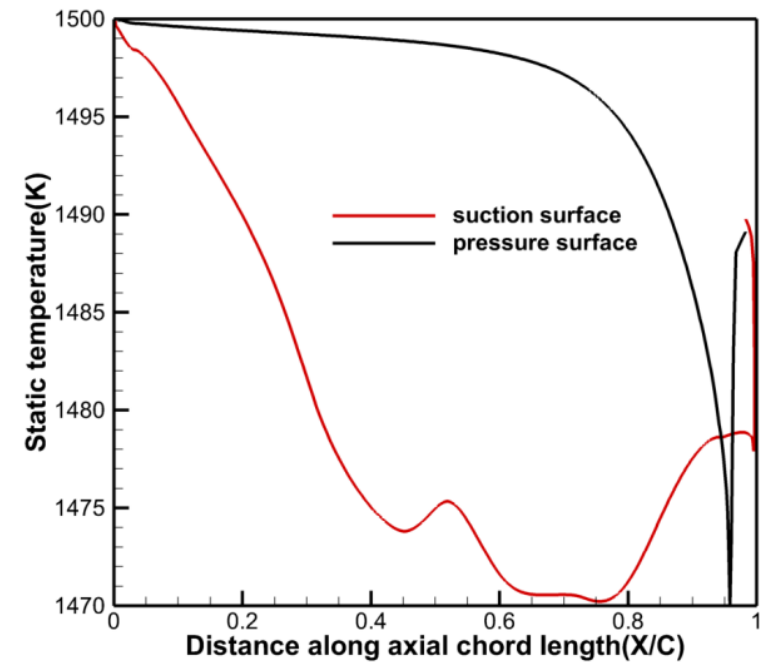

Figure 7 Temperature distribution along the blade surface

\section{PERFORMANCE DEGRADATION OF THE BLADE DUE TO SURFACE ROUGHNESS}

After the above analysis, we come to two important conclusions: (1) most of the particles are deposited on the pressure surface of the turbine vane; (2) the blade pressure surface near the leading edge and tailing edge will get bigger roughness compared to other parts of the pressure surface. In order to figure out the effects of the ununiforn roughness on the blade aerodynamic performance, two roughness setting strategies on the pressure surface are adopted. One of them is setting average roughness calculated from deposition data and the other is based on the fitting curve of roughness heights acquired from the same deposition data. Obiviously, the second roughness on the blade pressure surface is variable. The equation(18) is used to calculate the local roughness height on the blade pressure surface.

$$
\mathrm{h}=\frac{m_{p}}{A \cdot \rho_{p}}
$$

where $m_{p}$ is the local deposition rate on the blade pressure surface and has the units of ug/s, A is the grid area which the particle deposits on with the units of $\mathrm{m}^{2}$ and the $\rho_{p}$ is the density of deposits assumed to be equal to that of the injected particles.

Two roughness setting methods on the blade pressure surface are adopted. The method one is setting uniform roughness calculated from deposition data. Table 5 shows the average roughness heights arrived from the local roughness heights using the equation(19) below. The method two is setting variable roughness based on fitting curve of the local roughness heights. Figure 8 shows the curve fitted by the same local roughness heights. Next, the two methods will be used to account for the effects of uniform and variable roughness on the blade aerodynamic performance. 


$$
R_{a}=\frac{1}{n} \sum_{i=1}^{n}\left|h_{i}\right|
$$

\begin{tabular}{|c|c|}
\hline $\begin{array}{c}\text { Deposition } \\
\text { time } \\
(\mathrm{min})\end{array}$ & $\begin{array}{c}\text { Arithmetic mean } \\
\text { deviation of } \\
\text { roughness height } \\
R_{a}(\mathrm{um})\end{array}$ \\
\hline 0.5 & 22.5 \\
\hline 1 & 45 \\
\hline 1.5 & 67.5 \\
\hline 2 & 90 \\
\hline 2.5 & 112.5 \\
\hline
\end{tabular}

\section{Table 5 Uniform roughness height on the pressure surface after different deposition time(roughness setting method one)}

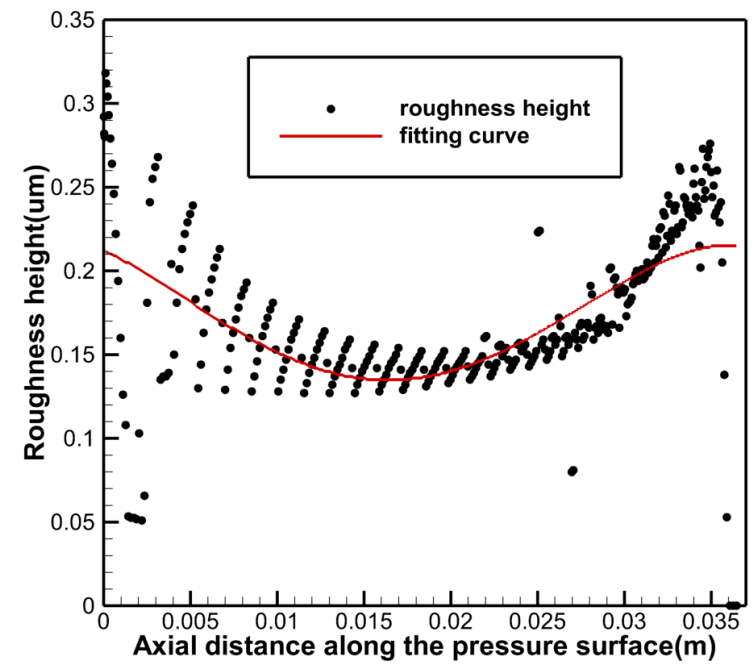

\section{Figure 8 Fitting curve derived from local roughness} height(roughness setting method two)

Figure 9 shows the mach number distributions along the blade pressure surface for the boundary condition (shown in Table 2 ) with roughness setting method one. Figure 10 shows the results under the same boundary condition with roughness setting method two. The data shown in the two figures are calculated after different deposition time. Apparently, the mach number along the blade pressure side is subsonic and an adverse pressure gradient does not occur which means that there is a good flow acceleration in this region. Besides, all the curves shown in the two figures are almost overlapping. This means that the increased roughness after short period of deposition time has little effects on the mach number distributions and the static pressure distributions along the blade surface. The result is consistent with the conclusion of Kind et al(1996) and Boyle and Senyitko(2003), which is that roughness has only small effects on the turbine airfoil surface static pressure distribution. Basing on this conclusion, it is reasonable to recognize the deposition rate on the blade pressure surface to be constant. So the roughness height after short deposition time can be obtained by multiplying deposition rate with depostion time directly.

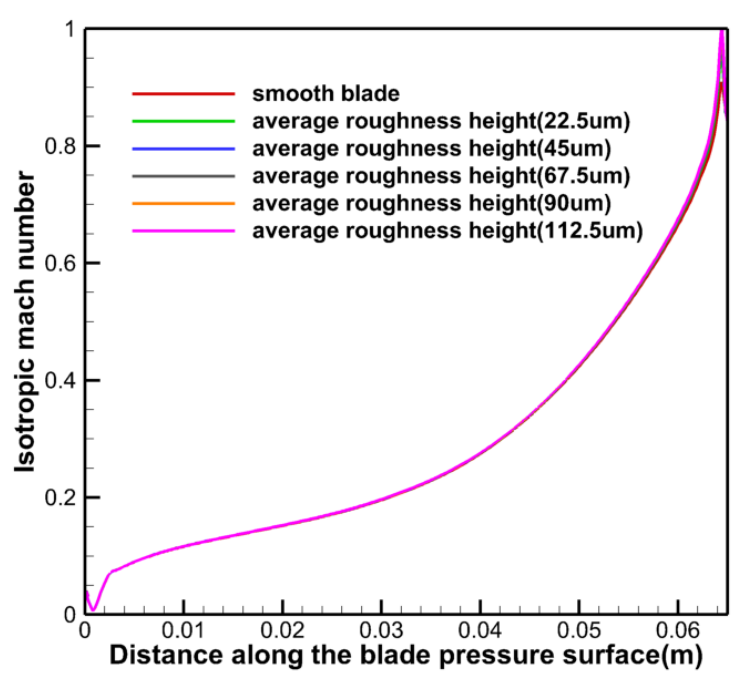

Figure 9 Mach distributions along the blade pressure surface with different roughness heights(roughness setting method one)

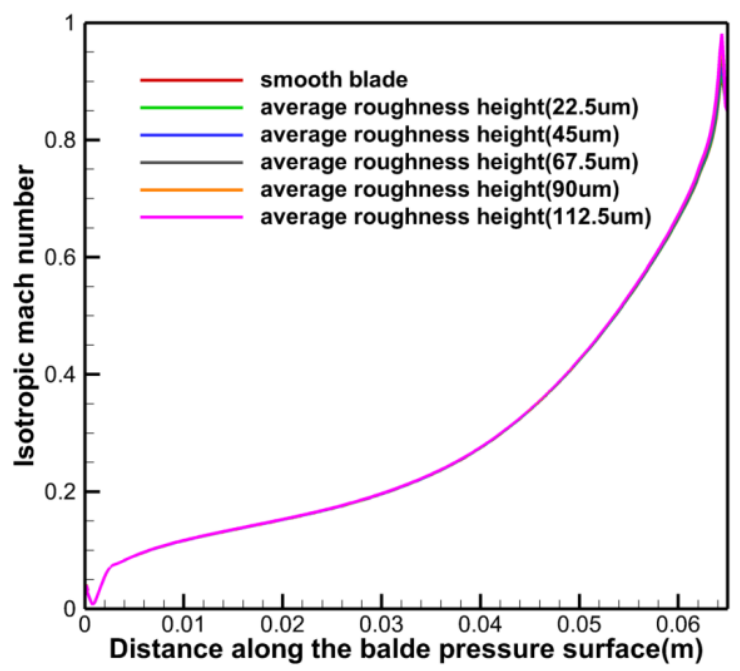

\section{Figure 10 Mach on the blade pressure surface with different roughness heights (roughness setting method two)}

Figure 11 and Figure 12 show the pressure surface friction coefficient using two roughness setting methods. The surface friction coefficient is defined as equation (20) where $F_{S}$ is the local wall shear stress, $\rho_{\infty}$ is the density of the free stream and $U_{\infty}$ is the velocity of the free stream. It can be seen that surface friction coefficient increases along the blade pressure surface because of the increasing velocity shown in Figure 9 and Figure 10. Furthermore, it is also found that the surface friction coeffcient on the pressure surface becomes 
increased as the roughness increases because the increasing roughness on the blade surface augments the obstruction drag to the fluid. Comparing the data in the two figures, the surface friction coefficient by the use of roughness setting method one increases faster. One of the possible reasons is that the uniform roughness has over-predicted the actual local roughness in most part of the pressure surface. It means that numerical calculation deploying the uniform roughness on the blade surface may cause a misleading prediction of the local surface friction.

$$
C_{f}=\frac{F s}{0.5 \rho_{\infty} U_{\infty}}
$$

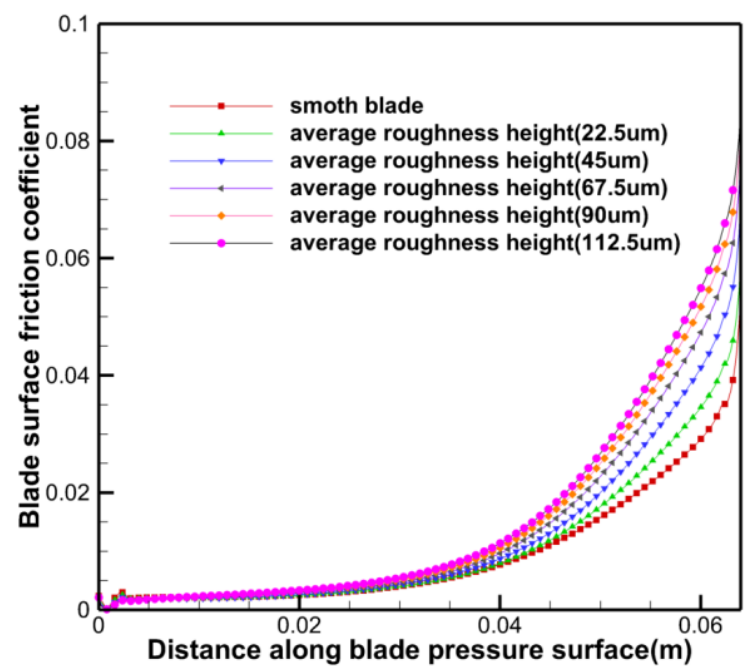

Figure 11 friction coefficient along the pressure surface with different roughness heights (roughness setting method one)

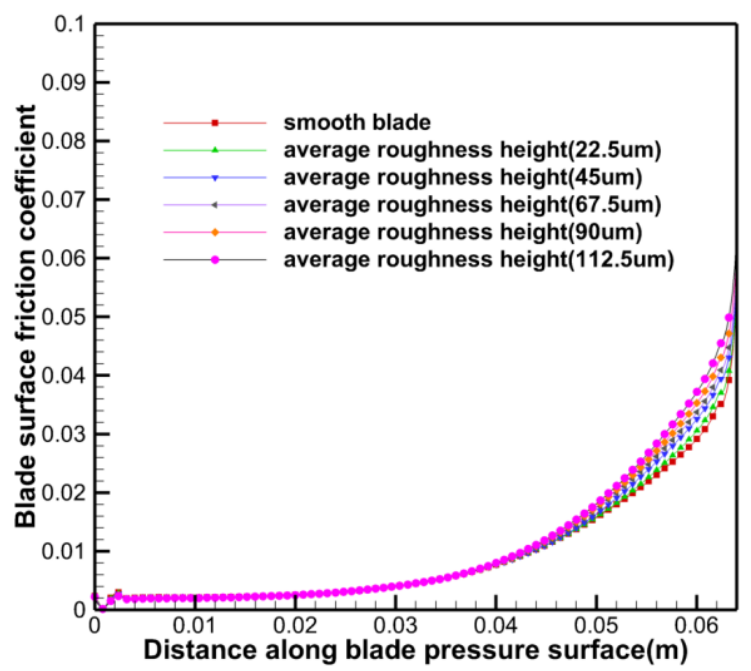

Figure 12 friction coefficient along the pressure surface with different roughness heights (roughness setting method two)
Figure 13 and Figure 14 show the local total pressure coefficient which is defined as equation (21) along exit pitch of the blade using two roughness setting methods. In equation (21), $p_{02}$ represents the local total exit pressure, $p_{01}$ represents the total inlet pressure, $\rho_{2}$ and $U_{2}$ are the exit density and exit velocity, respectively. In order to compare the two roughness setting methods better, the massaveraged total pressure coefficient was calculated. The result was showed in Figure 15. According to the last three figures, we can come to the conclusion that the downstream total pressure decreased as the roughness increased and that the decrease in the total pressure caused by uniform roughness was higher than that caused by variable roughness. It means that variable roughness placed on the blade pressure surface has smaller effects on the profile loss than that caused by the uniform roughness. Qian Zhang and Ligrani(2004) and Kind et al(1996) came to the same conclusion when they studied the effects of variable roughness on the profile losses of turbine blade.

$$
\mathrm{W}=\frac{p_{02}-p_{01}}{0.5 \rho_{2} U_{2}^{2}}
$$

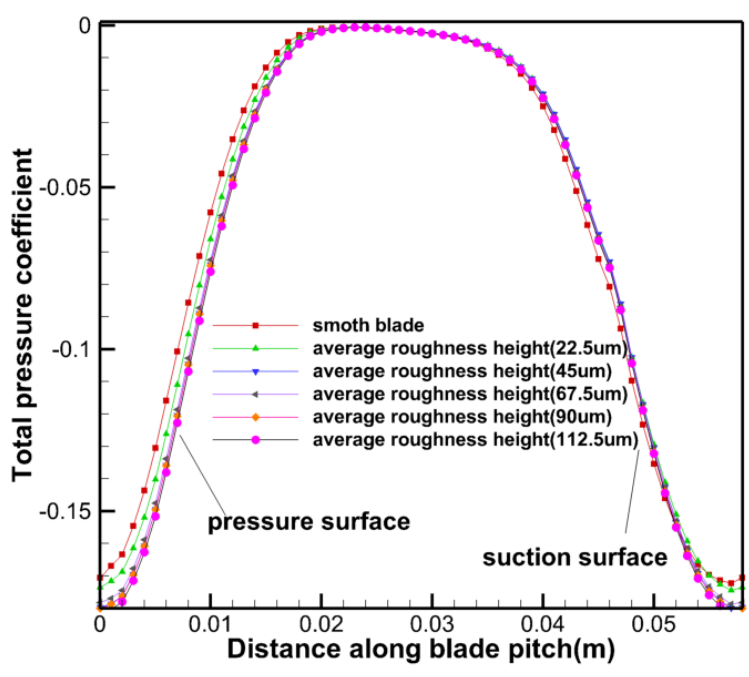

Figure 13 Total pressure coefficient along outlet with different roughness heights (roughness setting method one) 


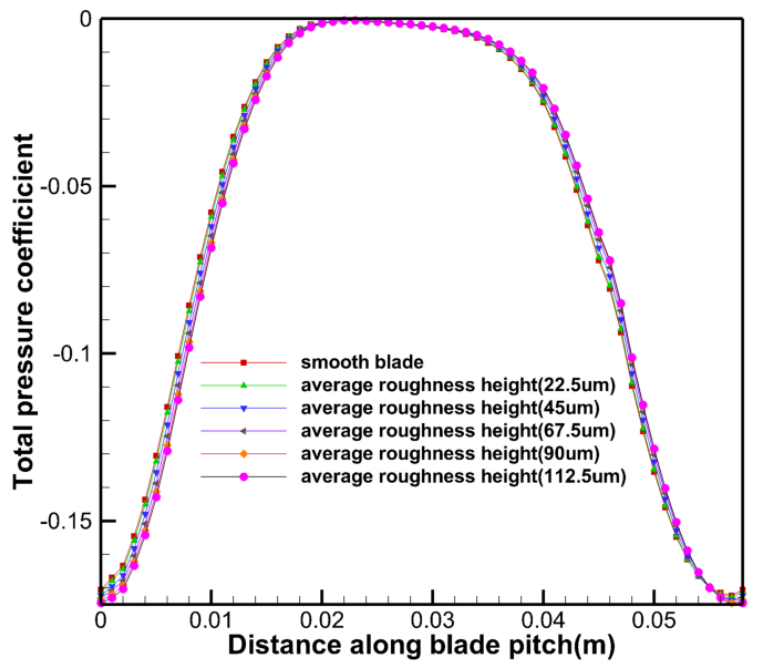

\section{Figure 14 Total pressure coefficient along outlet with different roughness heights (roughness setting method two)}

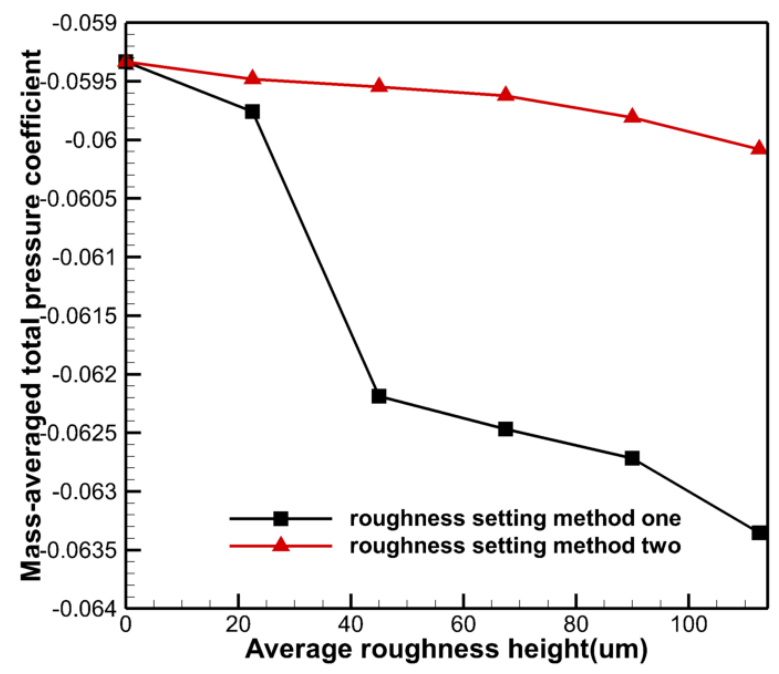

Figure 15 Mass-averaged total pressure coefficient with different roughness heights

\section{CONCLUSIONS}

The critical velocity sticking model was employed to study the characteristic of particle deposition on a transonic turbine guide vane. Then the blade pressure surface was set uniform and variable roughness based on the deposition data and then the effects of uniform and variable roughness on the turbine aerodynamic performance are investigated numerically. It was found that:

The particles are mostly deposited on the blade pressure surface and hardly deposited on the blade suction surface.
The particle deposition rate along the blade surface fluctuated sharply. The result is causing variable roughness on the blade surface.

Both uniform and variable roughness have little effects on the mach and static pressure on the blade pressure surface. As the roughness increased, both the surface friction coefficient on the blade pressure and total pressure losses increased. The variable roughness has smaller effects on the blade aerodynamic performance than those caused by uniform roughness on the blade pressure surface.

\section{NOMENCLATURE}

RANS Reynolds-Averaged Navier-Stokes

CFD Computational Fluid Dynamics

DPM Discrete Phase Modeling

$V_{c r} \quad$ Critical Velocity

E Composite Young's Modulus

D Diameter

$\bar{D} \quad$ Characteristic Diameter

T Temperature

e Restitution Parameter

u Wall Shear Velocity

$\rho \quad$ Density

$\beta \quad$ Impingement Angle

Y Mass Fraction

n Spread Number

c Specific Heat

K Thermal Conductivity

h Roughness Height

A Area

$\mathrm{m} \quad$ Deposition Rate

R Arithmetic Mean Deviation of Roughness Height

N Numbers of Particles

C Surface Friction Coefficient

U Velocity of Free Stream

F Wall Shear Stress

W Total Pressure Coefficient

\section{ACKNOWLEDGMENTS}

The authors are grateful for the support of this work provided by professor Zheng and professor Yang.

\section{REFERENCES}

Abuaf, N., Bunker, R. S., and Lee, C. P., (1998), Effects of Surface Roughness on Heat Transfer and Aerodynamic Performance of Turbine Airfoils, ASME J.Turbomach., 120, pp. 522-529.

Arts, T. , Lambert, d. R. M. , \& Rutherford, A. W. . (1990). Aero-thermal investigation of a highly loaded transonic linear turbine guide vane cascade: a test case for inviscid and viscous flow computations. Nasa Sti/recon Technical Report N, 91(29), 48-54. 
Barker BB, Casaday BB, Shankara PP, Ameri AA, Bons JP. (2012), Coal Ash Deposition on Nozzle Guide Vanes-Part II: Computational Modeling. ASME. J. Turbomach. 135(1):011015-011015-9. doi:10.1115/1.4006399.

Boyle, R. J., and Senyitko, R. G., (2003), Measurements and Predictions of Surface Roughness Effects on Turbine Vane Aerodynamics, ASME Paper No.GT-2003-38580.

Bölcs AA, Sari OO, (1998). Influence of Deposit on the Flow in a Turbine Cascade. ASME. J. Turbomach.110(4):512-519. doi:10.1115/1.3262225.

Bons, J. P., (2010), A Review of Surface Roughness Effects in Gas Turbines, ASME J. Turbomach., 132, p. 021004.

Dunn, M. G., Baran, A. J., and Miatech, J., (1996), Operation of Gas TurbineEngines in Volcanic Ash Clouds, ASME J. Eng. Gas Turbines Power, 118, pp. 724-731.

El-Batsh, Hesham. (2001). Modeling Particle Depositon on Compressor and Turbine Blade Surfaces, Ph.D. Thesis, Vienna University of Technology, Vienna, Austria.

El-Batsh H, Haselbacher H. (2002) Numerical Investigation of the Effect of Ash Particle Deposition on the Flow Field Through Turbine Cascades. ASME. Turbo Expo: Power for Land, Sea, and Air, Volume 5: Turbo Expo 2002, Parts A and B ():1035-1043. doi:10.1115/GT2002-30600.

Grant, G. and Tabakoff, W. (1975). Erosion prediction in turbomachinery resulting from environmental solid particles. Journal of Aircraft, 12(5):471-478.

Kawagishi, H., Nagao, S. and Kawasaki, S. (1992), Performance Evaluation of Geothermal Steam Turbine with Scale Deposits, PWR-Vol. Steam Turbine-Generator Developments for the Power Generation Industry, ASME,pp. 69-73.

Kind, R. J., Serjak, P. J., and Abbott, M. W. P., (1996), Measurements andPrediction of The Effects of Surface Roughness on Profile Losses and Deviation in a Turbine Cascade, ASME Paper No. 95-GT-203.

Schlichting, H., (1979), Boundary Layer Theory, 7th ed., McGraw-Hill, New York.

Tabakoff, W., (1987), “Compressor Erosion and Performance Deterioration,” ASME J. Fluids Eng., 109(3), pp. 297-306.

Tabakoff, W. , Metwally, M., (1992), Coating Effect on Particle Trajectories and Turbine Blade Erosion[J]. Journal of Engineering for Gas Turbines and Power, 114(2):250.

Tafti, D. K., and Sreedharan, S. S., (2010), Composition Dependent Model for the Prediction of Syngas Ash Deposition With Application to a Leading Edge Turbine Vane, Proceedings of the ASME Turbo Expo 2010: Power for Land, Sea, and Air, (GT2010), Glasgow, UK, June 14-18, ASME Paper No. GT2010-23655.

Walsh, W., Thole, K., and Joe, C. (2006). Effects of sand ingestion on the blockage of filmcooling holes. In ASME Turbo Expo 2006: Power for Land, Sea, and Air, pages 8190.American Society of Mechanical Engineers.

Zhang, Q., and Ligrani, P. M., (2004), Effects of Mach Number and Surface Roughness on the Aerodynamic Losses of a Symmetric Transonic Turbine Airfoil, J. Propul. Power, 20, pp. 1117-1125. 